\title{
Originals
}

\section{Potentiating effect of metformin on insulin-induced glucose uptake and glycogen metabolism within Xenopus oocytes}

\author{
D. Detaille ${ }^{1}$, N. Wiernsperger ${ }^{2}$, P. Devos ${ }^{1}$ \\ ${ }^{1}$ Unité de Recherche en Biologie des Organismes, Laboratory of Comparative Biochemistry and Physiology, \\ Facultés Universitaires Notre-Dame de la Paix (FUNDP), Namur, Belgium \\ ${ }^{2}$ Lyonnaise Industrielle Pharmaceutique (LIPHA) Laboratories, Lyon, France
}

Summary Xenopus laevis oocytes were chosen as the in vitro model for this study with the aim of reconsidering metformin action on the main insulin-responsive glucose pathway. Metformin alone, when present at a therapeutic dose $(20 \mu \mathrm{mol} / \mathrm{l})$ in the incubation medium, did not alter the basal rate of glucose uptake or of glycogen synthesis as measured by $\left[\mathrm{U}^{14} \mathrm{C}\right] \mathrm{D}$ glucose incorporation. The drug had no effect on the main rate-limiting enzyme implicated in this pathway, i.e. glycogen synthase. In contrast, when combined with $2 \mu \mathrm{mol} / 1$ insulin, metformin led to a specific rise of both free and stored glucose, by 42.4 and $102.3 \%$ respectively. Moreoever, a short-term preincubation of mature oocytes with metformin, but in the absence of glucose, enhanced significantly the amount of syn- thase $a$ when stimulated by $50 \mathrm{nmol} / 1$ insulin (basal $17.4 \pm 5.7 \%$, metformin $21.3 \pm 4.1 \%$, insulin $31.2 \pm$ $4.6 \%$, metformin together with insulin $62.7 \pm 4.2 \%$, $p<0.005, n=5)$. Interestingly, the microinjection of this biguanide, at a final concentration of $20 \mathrm{nmol} / \mathrm{l}$, allowed a similar biochemical response. These data clearly suggest that metformin could act primarily at postreceptor steps which are thought to be key sites in controlling the cellular glucose homeostasis. [Diabetologia (1998) 41:2--8]

Keywords Metformin, insulin receptor, glucose transport, glycogen synthase, glycogenesis, Xenopus laevis oocytes.
The potent anti-diabetic biguanide metformin is an oral antihyperglycaemic drug that is extensively used in the treatment of diabetes mellitus. The ability of metformin to lower blood glucose concentration via a decrease in hepatic glucose production is predominantly attributed to an improvement of the peripheral tissue sensitivity to insulin [1, 2]. However, and despite its widespread use, the mechanism of metformin action still remains poorly understood at the cellular level.

Recent advances in the understanding of molecular mechanisms underlying the process of insulin signalling allowed to specify better some metabolic actions of the biguanide. Results from studies on var-

Received: 21 April 1997 and in revised form: 14 August 1997

Corresponding author: Dr. D.Detaille, Laboratory of Comparative Biochemistry and Physiology, Facultés Universitaires Notre-Dame de la Paix, Rue de Bruxelles, 61, B-5000 Namur, Belgium

Abbreviations: GS, Glycogen synthase; GVBD, germinal vesicle breakdown; MBS, modified Barth's solution; GLUT, glucose transporter. ious insulin-sensitive cells or tissues explained the efficiency of metformin as a potentiation of hormonal action [3]. This partly proceeded from glucose uptake through a stimulatory effect associated with either an enhanced recruitment of responsive transporters such as GLUT4 or a change in the affinity of carriers [4]. Moreover, metformin acted on different biochemical pathways linked to the main metabolic functions of insulin, namely the lipid [5] and protein synthesis [6] as well as the carbohydrate metabolism $[7,8]$.

However, instead of using target somatic cells such as hepatocytes or adipocytes, another approach to characterize the synergism between metformin and insulin is the application of the Xenopus laevis oocyte as an experimental tool. This kind of cell, by its large amount of stored substances including glycogen and by other physiological features, provides an attractive model to elucidate the possible involvement of metformin in two major biological processes initiated by insulin, i. e. cell maturation and glycogen metabolism. Grigorescu and colleagues [9] were the first to observe that treatment with metformin potentiated the 
insulin action on oocyte maturation, without changing insulin binding. More recently, two other groups of researchers $[10,11]$ strengthened this observation by demonstrating that, combined with the hormone, metformin was able to stimulate insulin action in two ways: it enhanced in a dose-dependent manner the rate at which insulin induces oocytes to undergo meiosis and it stimulated the number of cells that respond to insulin by increasing the final percentage of germinal vesicle breakdown (GVBD). Microinjection of metformin into oocyte $(120 \mathrm{nmol} /$ cell $)$ also amplified insulin-mediated GVBD, even if the intensity of the process was inferior to that observed in eggs incubated in the presence of metformin associated with the hormone. On the other hand, previous studies from our laboratory showed that some metabolic events involved in the regulation of glycogen biosynthesis are concomitant with the mitogenesis triggered after hormonal induction [12]. These results suggest that the mechanisms set up by insulin to activate glycogenesis rely on a cascade of enzymatic reactions that generate the appropriate conditions required for activation of glycogen synthase (GS), the enzyme which catalyses the rate-limiting step of this metabolic chain [13,14]. Regarding the mode of action of metformin on this pathway little information is actually reported. Nevertheless, in the light of preliminary findings on maturation and of our own observations on oocyte metabolism, it is likely that metformin may act by modulating one or several specific targets of insulin probably located inside the cell and which could affect not only the growth process as effectively demonstrated but also the biochemical pathways depending on insulin, the most relevant among them being presumably the storage of glucose as glycogen.

In this context, the goal of the present study was twofold. First, we checked the validity of the hypothesis according to which metformin is able to potentiate therapeutically both the uptake of glucose and the biosynthesis of glycogen, depending on the presence or absence of insulin. A second approach was to examine the impact of the drug, added to the incubation medium or directly microinjected into $\mathrm{Xe}$ nopus oocytes, on GS activity, since insulin-mediated glycogenesis is under tight regulation of this enzyme.

\section{Materials and methods}

Materials. Metformin hydrochloride was a gift from LIPHA Laboratories (Lyon, France). D-[U- $\left.{ }^{14} \mathrm{C}\right]$ glucose and uridine diphospho-D-[U-14 C] glucose were from Amersham, 3-0 methyl-D-[U- $\left.{ }^{14} \mathrm{C}\right]$ glucose from Dupont-New England Nuclear Corporation (Boston, Mass., USA). Scintillant liquid Aqualuma was obtained from Lumac LSC (Groningen, The Netherlands). Type IA collagenase, porcine insulin and all other reagent grade chemicals were purchased from Sigma Chemical Co. (St. Louis, Mo., USA), except for EDTA which was from Merck (Darmstadt, Germany).
Isolation and preparation of Xenopus oocytes. Xenopus laevis females were obtained from African Xenopus Facility (Cape Town, South Africa). Adult female frogs were anaesthetized by immersion in ice water for 20--30 min. After decapitation, the ovarian tissue was taken off and placed directly in a modified Barth's solution (MBS buffer in mmol/l: $88 \mathrm{NaCl}, 1 \mathrm{KCl}$, $2.4 \mathrm{NaHCO}_{3}, \quad 0.33 \mathrm{Ca}\left(\mathrm{NO}_{3}\right)_{2}, \quad 0.41 \mathrm{CaCl}_{2}, \quad 0.82 \mathrm{MgSO}_{4}$, 10 Hepes, pH 7.6). Oocytes, obtained by dissection of the ovarian membranes, were selected according to their development stages [15]. For the present studies, eggs in stages III, IV and $\mathrm{V}$, VI were chosen. After this selection, the oocytes underwent a treatment with $2 \mathrm{mg} / \mathrm{ml}$ collagenase in $\mathrm{Ca}^{2+}$-free MBS, either for $2 \mathrm{~h}$ at ambient temperature or overnight in a cold room, in order to remove the surrounding follicle cells and remaining membrane fragments. The removal of calcium ions from the physiological solution was required to avoid activation of other proteases associated with the preparation of collagenase. Once selected and treated, the eggs were thoroughly rinsed in MBS.

Oocyte glycogenesis experiments. Groups of 10 to 60 maturating oocytes (corresponding to stages III and IV) were first preincubated for $90 \mathrm{~min}$ at room temperature in $2 \mathrm{ml} \mathrm{MBS}$ containing either $20 \mu \mathrm{mol} / \mathrm{l}$ metformin combined with $2 \mu \mathrm{mol} / \mathrm{l}$ insulin or each of both substances separately at the same concentrations. A control experiment was performed by incubating the eggs in $2 \mathrm{ml} \mathrm{MBS}$ for $90 \mathrm{~min}$. Afterwards, $2 \mathrm{mmol} / \mathrm{l} \mathrm{D}$-[U${ }^{14} \mathrm{C}$ ] glucose $(287 \mathrm{mCi} / \mathrm{mmol})$ was added in the control and test tubes, and the oocytes were incubated for 60 more min. The reaction was stopped by rapidly washing the oocytes twice in $10 \mathrm{ml}$ of ice-cold fresh MBS. The cells were then solubilized in $1 \mathrm{ml}$ of $2.5 \%$ SDS. Aliquots from the lysat were taken for determination of the total intracellular radioactivity. Rates of glycogenesis were estimated by measuring the radioactivity incorporated into glycogen from $\mathrm{D}-\left[\mathrm{U}-{ }^{14} \mathrm{C}\right]$ glucose present in the final incubation. Glycogen was precipitated on $2 \times 2 \mathrm{~cm}$ Whatman ET31 filter paper in the presence of $66 \%(\mathrm{v} / \mathrm{v})$ cold ethanol. This was followed by two washes of $20 \mathrm{~min}$ each in the same solution. Radioactivity associated with glycogen was then calculated by liquid scintillation counting (Beckman Instruments, Fullerton, Calif., USA).

Kinetic analysis of hexose uptake. Groups of 8 to 20 oocytes were transferred into $2 \mathrm{ml}$ of MBS either alone or containing insulin in the absence or presence of metformin. After incubation for $90 \mathrm{~min}$ at room temperature, 3-O -methyl-D-[U- $\left.{ }^{14} \mathrm{C}\right]$ glucose $(325 \mathrm{mCi} / \mathrm{mmol})$ was added at various concentrations for a further $10 \mathrm{~min}$. The reaction was stopped and the intracellular radioactivity was determined as described above. Lineweaver-Burk form was used to calculate both $\mathrm{V}_{\max }$ and $\mathrm{K}_{\mathrm{m}}$.

Glycogen synthase assay. Experiments, intended to test the possible link of metformin to insulin-induced GS activity, were carried out on full-grown oocytes (stages V and VI) according to the same procedure as above, except that glucose was removed from the incubation medium, and oocytes were disrupted at $4^{\circ} \mathrm{C}$ by sonication (Virsonic model $n^{\circ} 150$; The Virtis Co., Inc, Gardiner, N.Y., USA) in $1 \mathrm{ml}$ of appropriate buffer (in mmol/l: 50 Tris pH 7.8, 5 EDTA, 250 sucrose). After homogenization in glass tubes, the samples were centrifuged at $16000 \mathrm{~g}$ for $15 \mathrm{~min}$ at $4^{\circ} \mathrm{C}$. The GS activity of each extract was then assayed following a method previously described [16] via the incorporation of $\mathrm{D}-\left[\mathrm{U}-{ }^{14} \mathrm{C}\right]$ glucose from uridine diphospho-D-[U-14 D] glucose into glycogen. Briefly, one volume of sample was added to two volumes of assay medium $(50 \mathrm{mmol} / \mathrm{l}$ Tris pH 7.8 containing, at final concentrations, $5 \mathrm{mmol} / \mathrm{l}$ EDTA, $7 \mathrm{mmol} / \mathrm{l}$ uridine diphospho-D-[U- $\left.{ }^{14} \mathrm{C}\right]$ glucose 
$(287 \mathrm{mCi} / \mathrm{mmol})$ and $1 \%$ glycogen $)$. This mixture was incubated for $10--15 \mathrm{~min}$ at $30^{\circ} \mathrm{C}$ and the reaction was stopped by spotting aliquots onto $2 \times 2 \mathrm{~cm}$ Whatman ET31 filter papers, which were immediately immersed in a $66 \%$ ethanol cold bath. The washing solution was changed two or three times over $1 \mathrm{~h}$. The papers were then rinsed in acetone, dried, placed into vials containing $4 \mathrm{ml}$ of scintillant liquid Aqualuma and the radioactivity was measured in a scintillation counter. Total GS activity was measured in the presence of $7 \mathrm{mmol} / \mathrm{l}$ glucose 6-phosphate, whereas the active form (or $a$-form) of GS was assayed in the presence of $10 \mathrm{mmol} / 1 \mathrm{Na}_{2} \mathrm{SO}_{4}$. The activity of both total and $a$-forms was expressed in nanomoles of $\mathrm{D}-\left[\mathrm{U}-{ }^{14} \mathrm{C}\right]$ glucose incorporated into glycogen per hour and per $g$ of wet weight. The $a$-form (also called synthase $a$ ) activity was also expressed as a percentage of the total enzyme activity.

Microinjection of metformin. The type of apparatus used for microinjection experiments consisted of a micromanipulator (Leitz, Wetzlar, Germany) combined with an injection system [17]. Injection needles were pulled with a Micro Electrode Puller (C. F. Palmer Ltd, London, UK). A diluted solution of metformin was directly injected into each mature oocyte in order to reach a final intracellular concentration corresponding to $20 \mathrm{nmol} / \mathrm{l}$ metformin, the intracellular free volume of such eggs being evaluated at $500 \mathrm{nl}$ as described elsewhere [18]. Control oocytes were injected with an equivalent quantity of MBS. About 15 min after injection of the biguanide (or buffer), the cells were incubated for $60 \mathrm{~min}$ in $2 \mathrm{ml} \mathrm{MBS}$ containing either $50 \mathrm{nmol} / \mathrm{l}$ insulin or not. At the end of this incubation, oocytes underwent the same treatment and the activity of synthase $a$ was measured on extracts as earlier reported in the text.

Statistical analysis. Values were expressed as mean \pm SEM and statistical significance was ascertained by a two-tailed Student's $t$-test.

\section{Results}

Effect of metformin on glucose uptake and its incorporation into glycogen. The goal of our basic experiments was to check the positive role of metformin, when used at a therapeutically relevant concentration, on the metabolic action triggered by insulin in maturing Xenopus laevis oocytes (stages III and IV of development). For these studies, 10 to 60 defolliculated eggs were incubated at room temperature for 90 min either in the presence of the biguanide alone $(20 \mu \mathrm{mol} / \mathrm{l})$ or in combination with the hormone $(2 \mu \mathrm{mol} / \mathrm{l})$. Then $2 \mathrm{mmol} / \mathrm{l} \mathrm{D}-\left[\mathrm{U}_{-}{ }^{14} \mathrm{C}\right]$ glucose was added in order to evaluate the total amount of glucose transported across the oocyte membrane and its fraction incorporated into glycogen. Data from Table 1 clearly reveal first that, at this therapeutic concentration, the drug is not able to increase by itself the basal rates of glucose uptake and glycogen synthesis. In contrast, metformin combined with $2 \mu \mathrm{mol} / \mathrm{l}$ insulin strongly enhances both metabolic events. This table also shows that more than $40 \%$ of the internalized sugar, due specifically to the action of metformin, is used for the synthesis of glycogen. In fact, out of 125 pmol of glucose taken up per hour by the oocyte
Table 1. Effect of metformin on glucose uptake and glycogen synthesis within oocytes

\begin{tabular}{llc}
\hline & $\begin{array}{l}\text { Total glucose trans- } \\
\text { port across oocyte } \\
\text { membrane } \\
\left(\mathrm{pmol} \cdot \mathrm{h}^{-1} \cdot \text { oocyte }^{-1}\right)\end{array}$ & $\begin{array}{l}\text { Amount of glucose } \\
\text { incorporated into } \\
\text { glycogen } \\
\left(\mathrm{pmol} \cdot \mathrm{h}^{-1} \cdot \text { oocyte }^{-1}\right)\end{array}$ \\
\hline Control & $129.1 \pm 8.9$ & $11.4 \pm 1.2$ \\
Metformin & $143.2 \pm 16.5$ & $14.8 \pm 2.7$ \\
Insulin & $301.8 \pm 28.2^{\mathrm{a}}$ & $51.3 \pm 4.9^{\mathrm{a}}$ \\
Metformin + Insulin & $426.8 \pm 29.3^{\mathrm{b}}$ & $104.1 \pm 8.8^{\mathrm{b}}$ \\
\hline
\end{tabular}

Maturing cells, either untreated (control) or stimulated by $2 \mu \mathrm{mol} / \mathrm{l}$ insulin, were incubated in the presence or absence of $20 \mu \mathrm{mol} / 1 \mathrm{metformin}$ before measuring rates of total glucose entry and glycogenesis as described in Methods. Results are the mean $\pm \operatorname{SEM}(n=4$, each conducted in duplicate).

${ }^{a}$ Insulin effect significant at $p<0.001$ compared to control basal conditions.

${ }^{\mathrm{b}}$ Metformin effect, in the presence of insulin, significant at $p<0.005$ compared to hormone effect alone

(the difference between underlined data in the left column), 53 pmol is subsequently transferred per hour to the growing glycogen molecule (the difference between underlined data in the right column). The hormone almost doubles the rate of glucose incorporation into glycogen whereas the effect due to the presence of metformin in conjunction with insulin reaches $266 \%$ of control (average values); this corresponds respectively to 39.4 and $82.7 \mathrm{pmol} \cdot \mathrm{h}^{-1}$. oocyte $^{-1}$ of glucose sequestered as glycogen. To then determine whether the activation of insulin-mediated glucose transport by metformin resulted from a change in the kinetic parameters for hexose, the dependence of 3- 0 -methylglucose uptake upon sugar concentration was investigated. The results presented in Figure 1 indicate that metformin had little effect on the $\mathrm{K}_{\mathrm{m}}$ for $3-0$-methylglucose $(2.5 \mathrm{vs} 2.4 \mathrm{mmol} / \mathrm{l})$ but elicited a further increase of the $\mathrm{V}_{\max }$ in relation to insulin effect alone (83.3 vs $62.5 \mathrm{pmol} \cdot$ oocyte $^{-1}$. $\left.\min ^{-1}\right) . \mathrm{V}_{\max }$ under basal conditions was estimated to $31.2 \mathrm{pmol} \cdot$ oocyte $^{-1} \cdot \mathrm{min}^{-1}$ and $\mathrm{K}_{\mathrm{m}}$ to $1.9 \mathrm{mmol} / \mathrm{l}$.

Effect of metformin on insulin-stimulated glycogen synthase activity. As glycogen synthase (GS) is the main rate-limiting enzyme involved in the hormonal regulation of glycogenesis, we next addressed the question whether metformin in vitro was able to potentiate insulin-induced GS activity in Xenopus oocytes. For these experiments we selected stages V and VI eggs, i.e. mature oocytes for which the observed enzymatic activity was very low and thus easily affected by the presence of agonists. After incubation under the same conditions as previously, except that glucose was withdrawn from the MBS buffer, oocytes were homogenized in an appropriate buffer intended to protect the activity of GS. After centrifugation, the extracts were assayed for GS activity as described in Methods. It should be mentioned that omis- 
Table 2. Effect of metformin on insulin-induced glycogen synthase activity

\begin{tabular}{llcc}
\hline & \multicolumn{2}{l}{ Glycogen synthase activity $\left(\mathrm{nmol} \cdot \mathrm{min}^{-1} \cdot \mathrm{g}\right.$ wet weight $\left.{ }^{-1}\right)$} & $\begin{array}{c}\text { Synthase } a \\
(\% \text { of total activity) }\end{array}$ \\
\cline { 2 - 3 } & Total activity & Active $(a)$ form & $18.5 \pm 5.1$ \\
Control & $245.8 \pm 15.9$ & $45.4 \pm 10.8$ & $22.4 \pm 6.6$ \\
Metformin $(20 \mu \mathrm{mol} / \mathrm{l})$ & $229.6 \pm 23$ & $51.3 \pm 14.2$ & $38.3 \pm 6.3$ \\
Insulin $(50 \mathrm{nmol} / \mathrm{l})$ & $242.6 \pm 20.4$ & $93.1 \pm 15.4^{\mathrm{a}}$ & $59.3 \pm 9.5$ \\
Metformin $(20 \mu \mathrm{mol} / \mathrm{l})+$ Insulin $(50 \mathrm{nmol} / \mathrm{l})$ & $240 \pm 22.6$ & $142 \pm 19.6^{\mathrm{b}}$ & $66.7 \pm 8.1$ \\
Insulin $(2 \mu \mathrm{mol} / \mathrm{l})$ & $235.7 \pm 19.2$ & $157.1 \pm 10.3^{\mathrm{a}}$ & $91.3 \pm 12.7$ \\
Metformin $(20 \mu \mathrm{mol} / \mathrm{l})+$ Insulin $(2 \mu \mathrm{mol} / \mathrm{l})$ & $232.1 \pm 25.9$ & $211.9 \pm 19.3^{\mathrm{b}}$ & \\
\hline
\end{tabular}

Intact ripe oocytes were incubated according to experimental conditions described under Methods section, before measuring the enzyme activity. For each treatment total $(a+b)$ and active $(a)$ forms of GS activity as well as the percentage of active form (i.e. synthase $a$ ) are given. Results are the mean \pm SEM $(n=4$ or 6$)$.

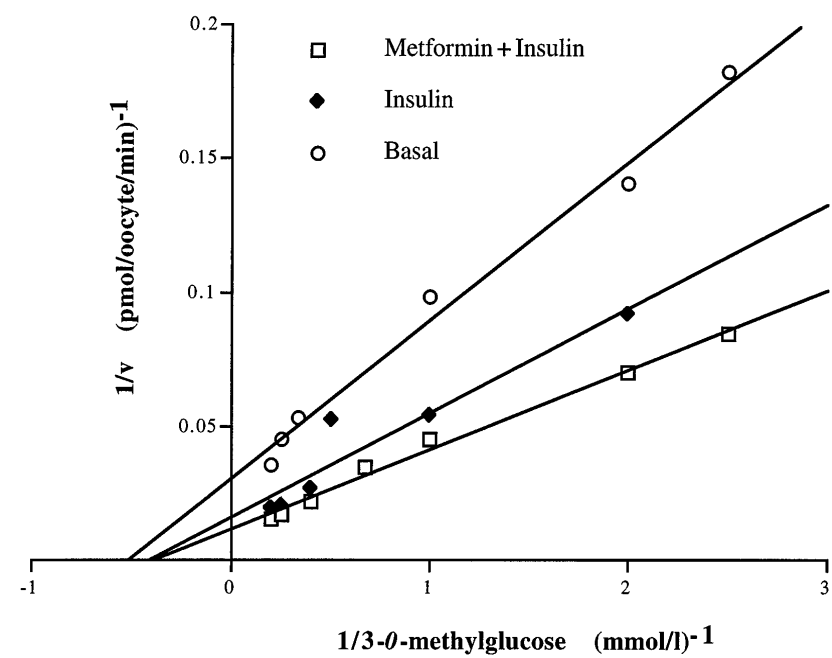

Fig.1. Lineweaver-Burk representation of concentration dependent 3-0-methylglucose transport into oocytes. The oocytes were first incubated for 90 min either in MBS alone or in MBS containing $2 \mu \mathrm{mol} / 1$ insulin in the presence or absence of $20 \mu \mathrm{mol} / \mathrm{l}$ metformin. Initial rates of hexose uptake were then measured after $10 \mathrm{~min}$, using two groups of 20 eggs per point

sion of glucose in this kind of study is justified by the fact that we were interested in testing the particular role of metformin on the stimulation of insulin-induced GS activity, independently of an overloading of sugar into oocytes. As shown in Table 2, metformin alone has no effect on the activation of GS. However, the drug increases significantly $(p<0.005)$ the amount of the $a$-form above the level reached in the presence of insulin. It is also important to notice that, whatever the treatment of the oocytes, total GS activity is not modified. Further characterizing the effects of metformin on the activation of GS, Figure 2 shows that the drug is able to enhance dose-dependently the activity of synthase $a$ when induced by insulin and this, at two concentrations of the hormone. However, for the highest concentration of insulin $(2 \mu \mathrm{mol} / \mathrm{l})$, a maximal activation of GS might be reached before metformin, present in the incubation medium, can exert its effect.
${ }^{\mathrm{a}}$ Insulin effect significant at $p<0.001$ compared to control basal conditions.

${ }^{\mathrm{b}}$ Metformin effect, in the presence of insulin, significant at $p<0.005$ compared to insulin effect alone

On the contrary, the increasing effect recorded with the low insulin level $(50 \mathrm{nmol} / \mathrm{l})$ over a broad metformin concentration range is more representative of the usual dose-response curve. This graph clearly demonstrates the potentiating effect of the biguanide: $20 \mu \mathrm{mol} / \mathrm{l}$ metformin with $50 \mathrm{nmol} / \mathrm{l}$ insulin give almost the same result (an increase of synthase $a$ activity by $60-80 \%$ ) as insulin alone when tested at a concentration 10 to 20 fold greater. In addition, it appears that a significant stimulation of insulin action $(p<0.01)$ occurs at metformin concentrations in the range of $0.08--3.3 \mu \mathrm{g} / \mathrm{ml}(0.5--20 \mu \mathrm{mol} / \mathrm{l})$ whereas maximal activation of GS activity is achieved at about 20 to $60 \mu \mathrm{mol} / \mathrm{l}$ (data not shown). It is noteworthy that higher concentrations of metformin $(100 \mu \mathrm{mol} / \mathrm{l}$ and more $)$ are no more effective since the biguanide abolishes the stimulatory effect of insulin.

In another set of experiments, we tried to determine the influence of the time sequence of metformin addition relative to insulin treatment. We therefore tested the efficiency of metformin on GS activity when it was present in the incubation medium of the eggs, either before or after insulin addition. A slight, but not significant, increase in GS activity was recorded when metformin was added about 0.5 - $1 \mathrm{~h}$ before insulin ( $62.7 \pm 4.1 \%$ of synthase $a, n=4)$, relative to what is observed when both compounds are added at the same time $(56.4 \pm 3.6 \%$ of synthase $a, n=3)$. In contrast, when the biguanide is added to the medium 15 min after insulin, the activity of GS is no more stimulated; indeed the percentage of synthase $a$ remains unchanged $(32.6 \pm 4 \%, n=4)$ compared to the response obtained with insulin alone $(31.1 \pm 4.5 \%$, $n=3$ ). Apparently, the enhancing effect only takes place in eggs submitted to a pretreatment with the biguanide before insulin addition.

Effect of injected metformin into oocytes on GS activity induced by insulin. In accordance with the recent work of Khan and colleagues [10], we further investigated the efficiency of metformin on hormonal action when the compound was directly microinjected into 


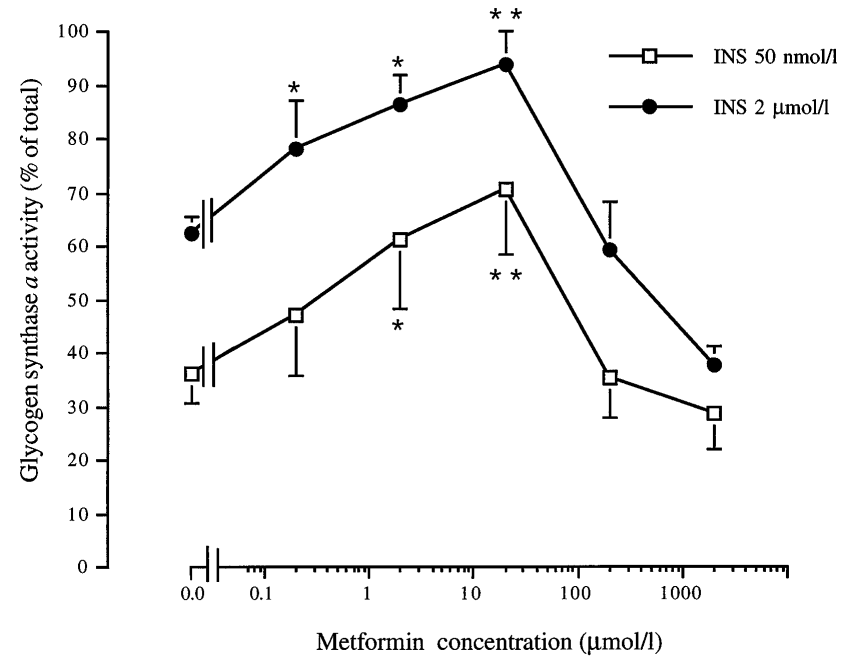

Fig. 2. Dose response curves for the effect of metformin on insulin-induced glycogen synthase $a$-form activity (expressed as $\%$ of total activity). The oocytes were incubated in the presence of the indicated concentrations of insulin, with increasing concentrations of metformin $(0--2 \mathrm{mmol} / \mathrm{l})$. After these treatments, each group of cells was homogenized and the samples obtained after centrifugation were then assayed for glycogen synthase activity as described in Methods. The results shown are the mean $\pm \operatorname{SEM}(n=4)$. * $p<0.01$, ** $p<0.005$ (both compared to insulin effects without metformin). The basal percent of $a$-form glycogen synthase activity in untreated oocytes was $21.3 \pm 3.8 \%$

oocytes. Hence, we compared the influence of metformin on insulin-mediated GS stimulation according to the method of drug application to these cells, either by simple incubation of metformin in the medium with insulin, or via its prior injection directly inside the eggs. The data presented in Figure 3 show that a preinjection of $20 \mathrm{nmol} / \mathrm{l}$ metformin per oocyte (corresponding to the estimated level present inside the eggs when incubated in $10 \mu \mathrm{mol} / \mathrm{l}$ metformin) potentiates insulin-induced GS activity. The mean increase in the level of synthase $a$ observed when oocytes are microinjected with metformin is significantly lower than with eggs incubated in the presence of the same substance $(p<0.01$ vs $p<0.005$, see Table 2 for comparison). Moreover, the injection of higher quantities of drug (up to $150 \mathrm{nmol} / \mathrm{l}$ metformin per oocyte) fails to increase the amount of synthase $a$ whereas the smallest active dose of microinjected metformin required to stimulate insulin action is around $1 \mathrm{nmol} / \mathrm{l}$. With respect to this last finding, one may hypothesize that metformin should be able to modify some molecular events specifically implicated in the insulin signalling cascade leading to an increased GS activity.

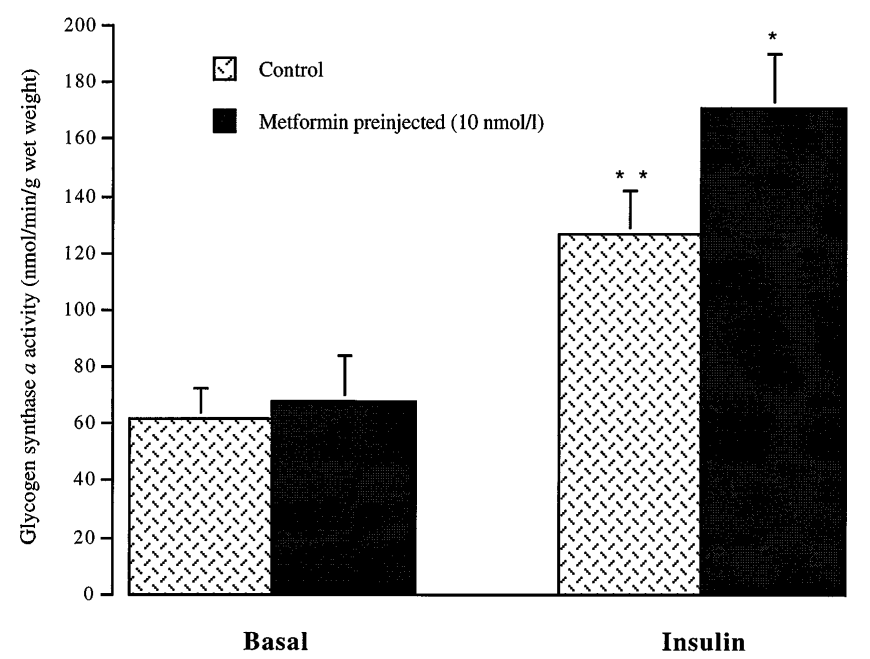

Fig.3. Effect of metformin microinjected into oocytes ( $\square$, either on basal glycogen synthase activity or on insulin-induced enzyme activity (플). Oocytes were first preinjected with metformin (at a final concentration of $20 \mathrm{nmol} / \mathrm{l}$ into each egg), or with an equivalent amount of MBS buffer. These groups of oocytes were then incubated for a further $60 \mathrm{~min}$ in the absence or presence of $50 \mathrm{nmol} / \mathrm{l}$ insulin, before assaying glycogen synthase activity in extracts as indicated in Methods. The data shown are the mean $\pm \operatorname{SEM}(n=4)$. ** $p<0.005$ (compared to basal activity without metformin), $* p<0.01$ (compared to insulin-stimulated activity). Total activity of glycogen synthase in this set of experiments is $246.9 \pm 10.3 \mathrm{nmol} \cdot \mathrm{min}^{-}$ 1 . $\mathrm{g}$ wet weight ${ }^{-1}$, whereas the basal activity of synthase $a$ is $64.6 \pm 10.5 \mathrm{nmol} \cdot \mathrm{min}^{-1} \cdot \mathrm{g}$ wet weight ${ }^{-1}$

\section{Discussion}

The main purpose of the present work was to re-assess the in vitro potentiating action of metformin on the most relevant metabolic function of insulin, namely glucose metabolism. We thus took advantage of the unique physiological features as well as some technical possibilities offered by our experimental model, the oocyte of Xenopus laevis. In addition to ease of handling, these large cells possess both insulin and insulin-like growth factor-1 (IGF-1) receptors [19] and, consequently, respond to the hormone or its agonist in a specific manner by increasing glucose transport [20] and by stimulating the maturation process [21]. As has been shown in our laboratory insulin is also the main induction signal required to promote glycogenesis in these sensitive cells, we therefore examined the effect of metformin treatment on this metabolic pathway mediated by the hormone.

In contrast to authors who have focused on the effects of the biguanide on glucose transport by working with non-metabolizable glucose analogues $[22,23]$, we used D-glucose that allowed us to analyse the fate of this sugar once taken up by the oocyte, following the hormonal signal combined with metformin. Indeed, it is not only the hexose transport itself but its incorporation into the glycogen, catalysed by 
the active form of glycogen synthase, which should warrant our model system. In agreement with many in vivo studies making use of typical hormone target cells from diabetic or healthy animals, we found that, while having no effect alone on the basal rates of glucose uptake and glycogen synthesis, metformin was able to increase both metabolic processes when combined with insulin. Interestingly, under such conditions, almost $50 \%$ (average value) of glucose entering the oocyte is converted into glycogen. This observation is essential in the context of our work. Indeed, as the predominant impairment of insulin-stimulated glucose metabolism in non-insulin-dependent diabetic subjects is a decrease in glucose storage [24], the in vitro stimulatory action of metformin, characterized by an improvement of insulin-mediated $\left[{ }^{14} \mathrm{C}\right]$ glucose incorporation into oocyte glycogen, may represent one of the mechanisms whereby the biguanide exerts, in vivo, its hypoglycaemic actions on sensitive cells. However, it was also suggested that biguanides behave in an opposite manner by exerting a glycogenolytic action [25]. This apparent discrepancy is obviously the result of quite different experimental conditions in terms of glucose content of the incubation medium, initial glycogen stores, duration of drug exposure and, mainly, concentration of biguanide used. In the present case, metformin at a therapeutic dose $(20 \mu \mathrm{mol} / \mathrm{l})$, i.e. corresponding to levels normally found in plasma [26], allowed results to be obtained which corroborate previous findings in favour of an improvement of insulin action [27--30].

The increased glycogen deposition in Xenopus oocytes could be accounted for by a stimulatory action of metformin at the level of the glucose transporters system, leading to a greater quantity of sugar pulled into glycogen through the action of GS. Since the present experiments were performed with maturing oocytes whose GS activity is already maximal in the absence of any treatment, we may assume that no change occurs at this level although we cannot exclude other cellular alterations. In agreement with recent studies, especially those revealing the ability of this anti-diabetic agent to restore a substantial defect in glucose uptake by erythrocytes, and more precisely in their capacity to store glucose as glycogen [31, 32], the present observations further support the evidence that metformin should primarily act by affecting the oocyte glucose transport system. From preliminary kinetic experiments with eggs deprived of GLUT4, it seems likely that the change in $\mathrm{V}_{\max }$ observed for the transport of 3- 0 -methylglucose should mainly reflect an alteration of the intrinsic properties of glucose carriers located at the cell surface, rather than a translocation of specific transporters from an intracellular compartment. Whatever the mechanism(s) proposed, the latter effects, presumably exerted by metformin alone, and insufficient by themselves to explain the whole process, must be a complement to those initi- ated by insulin to elicit an enhanced glycogen synthesis from increased glucose uptake.

In addition, recent observations tend to prove that GS is not only regulated by the rate of glucose transport, but that stimulation of GS also contributes to a net accumulation of this polysaccharide in response to insulin within glycogen rich tissues such as liver and muscle [33--35]. As glycogen is also a main end product of glucose metabolism in amphibian oocytes, we next studied the in vitro action of metformin on insulin-induced GS activity. Our results, similar to those previously reported [36], demonstrate that metformin stimulates the active form of this enzyme whereas it does not affect its total activity, thereby making it unlikely that enzyme expression is increased. Data from dose-response experiments achieved on fullgrown oocytes also provide clear evidence that metformin, at least in a therapeutic range, exerts its action by reducing insulin requirements for GS activation. At this point it is also interesting to note that higher metformin levels antagonize the action of insulin. This result is similar to those found by other researchers $[5,29]$ who observed that such doses of the drug (50 and $125 \mu \mathrm{g} / \mathrm{ml}$ ), applied to cultured rat hepatocytes, caused a significant reduction of glycogenesis stimulated or not by insulin. Nonetheless, the magnitude of the beneficial effect, that partly depends on the variability among ripe oocytes in terms of responsiveness to insulin and basal enzyme activity, is above all influenced by prevailing insulin levels. High doses of this hormone, ranging from 2 to $10 \mu \mathrm{mol} / \mathrm{l}$, should prevent any further increase of GS, even after a prolonged presence of metformin in the incubation medium deprived of glucose. We therefore chose a concentration of insulin close to physiological $(50 \mathrm{nmol} / \mathrm{l})$. This allowed a highly significant effect of the drug to be seen from which we may infer that metformin actually sensitized the oocytes to the action of insulin.

These findings clearly suggest that metformin may act upon the same pathway as insulin, by modulating some of its biochemical steps. This hypothesis is strongly supported by our microinjection experiments. For the first time, we observed that a prior injection of metformin into Xenopus oocytes (at a final intracellular concentration ranging from 1 to $20 \mathrm{nmol} / \mathrm{l}$ ) is effective in stimulating insulin-induced GS activity. Together with data on oocyte maturation which is also amplified by metformin once microinjected [10], it is tempting to speculate on an intracellular action of metformin, not necessarily dependent on insulin as suggested by some authors [11], but that must certainly be an essential prerequisite for the potentiation mechanism. These interesting observations are in some way complementary to results observed when metformin is added to the incubation medium prior to the hormone. To some extent, it is likely that the biguanide needs to penetrate into the cell membrane in order to exert either its own effects 
or the effects directly linked to most of cellular events triggered by insulin. However, the necessity for a complete internalization of the molecule is not yet demonstrated. It seems therefore worth performing further investigations in order to clarify this point.

In conclusion, our results firstly confirm the usefulness of the Xenopus laevis oocyte as an experimental pharmacological model, well designed to verify and investigate the mechanisms of the clinically well-known potentiation of insulin by metformin. Secondly, from the data presented here, it seems reasonable to conclude that under appropriate conditions metformin improves insulin action by modulating the intrinsic activity of pre-existing glucose transporters and/or by facilitating some early regulatory steps along the signalling chain linked to GS. It is thus conceivable that both events, which relative importance probably depends on the physiological setting of cells, should contribute to an enhanced metabolism of glycogen storage in response to metformin.

Acknowledgements. A contingent grant from LIPHA International, Lyon (France) to perform this study is greatly acknowledged.

\section{References}

1. Bailey CJ (1992) Biguanides and NIDDM. Diabetes Care 15: 755-772

2. Wiernsperger $N$ (1996) Preclinical pharmacology of biguanides. In: Kuhlman J, Puls W (eds) Oral antidiabetics. Series: handbook of experimental pharmacology, vol 129. Springer-Verlag Berlin, pp 305--358

3. Wiernsperger N, Rapin J-R (1995) Metformin-insulin interactions: from organ to cell. Diabetes Metab Rev 11: S 3--S 12

4. Matthaei S, Reibold JP, Hamann A et al. (1993) In vivo metformin treatment ameliorates insulin resistance: evidence for potentiation of insulin-induced translocation and increased functional activity of glucose transporters in obese (fa/fa) rat adipocytes. Endocrinology 133: 304--311

5. Melin B, Cherqui G, Bilvet MJ et al. (1990) Dual effect of metformin in cultured rat hepatocytes: potentiation of insulin action and prevention of insulin-induced resistance. Metabolism 39: 1089--1095

6. Zaibi MS, Padieu P, Cheesebeuf-Padieu M, El Baraka M, Wiernsperger N, Rapin J-R (1995) Metformin induces an agonistspecific increase in albumin production by primary cultured rat hepatocytes. Biochem Pharmacol 50: 775--780

7. Rossetti L, De Fronzo RA, Gherzi R et al. (1990) Effect of metformin treatment on insulin action in diabetic rats: in vivo and in vitro correlations. Metabolism 39: 425--435

8. Argaud D, Roth H, Wiernsperger N, Leverve XM (1993) Metformin decreases gluconeogenesis by enhancing the pyruvate kinase flux in isolated rat hepatocytes. Eur J Biochem 213: 1341--1348

9. Grigorescu F, Laurent A, Chavanieu A, Capony JP (1991) Cellular mechanism of metformin action. Diabete Metab 17: 146--149

10. Khan NA, Wiernsperger N, Quemener V, Moulinoux JP (1994) Internalization of metformin is necessary for its action on potentiating the insulin-induced Xenopus laevis oocyte maturation. J Endocrinol 142: 245--250

11. Stith BJ, Goalstone ML, Espinoza R, Mossel C, Roberts D, Wiernsperger N (1996) The antidiabetic drug metformin elevates receptor tyrosine kinase activity and inositol 1,4,5-trisphosphate mass in Xenopus oocytes. Endocrinology 137: 2990--2999
12. Debauche P, Barra B, Devos P (1994) Insulin but not progesterone promotes the biosynthesis of glycogen in Xenopus laevis oocytes. $\mathrm{J}$ Exp Zool 269: 1--11

13. Debauche P, Devos P (1990) Mise en évidenve d'une activité glycogène synthase au cours du développement d'oocytes de Xenopus laevis. Belgian J Zool 120: 19--20

14. Debauche P, Remy C, Devos P (1991) Phosphorylation as control mechanism for glycogen metabolism in Xenopus laevis oocytes. Arch Int Physiol Biochim Biophys 99: B54 (Abstract)

15. Dumont JN (1972) Oogenesis in Xenopus laevis (Daudin) I. Stages of oocyte development in laboratory maintained animals. J Morph 136: $153--180$

16. Thomas JA, Schendler KK, Larner J (1968) A rapid filter paper assay for UDP glucose-glycogen glucosyl transferase, including an improved biosynthesis of UDP- ${ }^{14} \mathrm{C}$-glucose. Anal Biochem 25: 486-499

17. Ansorge W (1982) Improved system for capillary microinjection into living cells. Exp Cell Res 140: 31--37

18. Stith BJ, Maller JL (1985) Increased intracellular pH is not necessary for ribosomal protein S6 phosphorylation, increased protein synthesis, or germinal vesicle breakdown in Xenopus oocytes. Dev Biol 107: 460--469

19. Hainaut P, Kowalski A, Giorgetti S, Baron V, Van Obberghen E (1991) Insulin and insulin-like growth factor-I (IGF-I) receptors in Xenopus laevis oocytes. Comparison with insulin receptors from liver and muscle. Biochem J 273: 673--678

20. Janicot M, Lane MD (1989) Activation of glucose uptake by insulin and insulin-like growth factor I in Xenopus oocytes. Proc Natl Acad Sci USA 86: 2642--2646

21. Grigorescu F, Bacara MT, Rouard M, Renard E (1994) Insulin and IGF-I signalling in oocytes maturation. Horm Res 42: 55--61

22. Klip A, Leiter LA (1990) Cellular mechanisms of action of metformin. Diabetes Care 13: 696--704

23. Galuska D, Zierath JR, Thorne A, Sonnenfeld T, Wallberg-Henriksson H (1991) Metformin increases insulin-stimulated glucose transport in insulin-resistant human skeletal muscle. Diabete Metab 17: 159--163

24. Shulman GI, Rothman DL, Jue T, Stein P, De Fronzo RA, Shulman RG (1990) Quantitation of muscle glycogen synthesis in normal subjects and subjects with non-insulin-dependent diabetes by $13 \mathrm{C} \mathrm{nu-}$ clear magnetic resonance spectroscopy. N Engl J Med 322: 223--228

25. Alengrin F, Grossi G, Canivet B, Dolais-Kitabgi J (1987) Effet inhibiteur de la metformine sur la réponse hépatocytaire à l'insuline et au glucagon. Diabete Metab 13: 591--597

26. Wilcock C, Bailey CJ (1994) Accumulation of metformin by tissues of the normal and diabetic mouse. Xenobiotica 24: 49--57

27. Lord JM, Puah JA, Atkins TW, Bailey CJ (1985) Postreceptor effect of metformin on insulin action in mice. J Pharm Pharmacol 37: 821--823

28. Bailey CJ, Puah JA (1986) Effect of metformin on glucose metabolism in mouse soleus muscle. Diabete Metab 12: 212--218

29. Purrello F, Gullo D, Buscema M et al. (1988) Metformin enhances certain insulin actions in cultured rat hepatoma cells. Diabetologia 31: 385--389

30. Jyothirmayi GN, Jayasundaramma B, Reddi AS (1992) In vivo glycogen and lipid synthesis by various tissues from normal and metformin-treated KK mice. Res Commun Chem Pathol Pharmacol 78: $113--116$

31. Rapin J-R, Lespinasse C, Yoa R, Wiernsperger N (1991) Erythrocyte glucose consumption in insulin-dependent diabetes: effect of metformin in vitro. Diabete Metab 17: 164--167

32. Yoa RG, Rapin JR, Wiernsperger N, Martinand A, Belleville I (1993) Demonstration of defective glucose uptake and storage in erythrocytes from non-insulin dependent diabetic patients and effects of metformin. Clin Exp Pharmacol Physiol 20: 563--567

33. Shulman RG, Bloch G, Rothman DL (1995) In vivo regulation of muscle glycogen synthase and the control of glycogen synthesis. Proc Natl Acad Sci USA 92: 8535--8542

34. Pugazhenthi S, Khandelwal RL (1995) Regulation of glycogen synthase activation in isolated hepatocytes. Mol Cell Biochem 149: 95-101 